Conference Paper

\title{
Online magnetization surface identification for a switched reluctance motor
}

Anuchin, A., Bogdanov, A., Demidova, G., Stolyarov, E., Surnin, D. and Vagapov. Y.

This is a paper presented at the Int. Universities Power Engineering Conference UPEC-2020, Torino, Italy, 1-4 Sept. 2020

Copyright of the author(s). Reproduced here with their permission and the permission of the conference organisers.

\section{Recommended citation:}

Anuchin, A., Bogdanov, A., Demidova, G., Stolyarov, E., Surnin, D. and Vagapov. Y. (2020), 'Online magnetization surface identification for a switched reluctance motor.' In: Proc. 55th IEEE Int. Universities Power Engineering Conference UPEC-2020, Torino, Italy, 1-4 Sept. 2020, pp. 1-5. doi: 10.1109/UPEC49904.2020.9209832 


\section{Online Magnetization Surface Identification for a Switched Reluctance Motor}

\author{
Alecksey Anuchin \\ Department of Electric Drives \\ Moscow Power Engineering Institute \\ Moscow, Russia \\ anuchin.alecksey@gmail.com \\ Evgeniy Stolyarov \\ Department of Electric Drives \\ Moscow Power Engineering Institute \\ Moscow, Russia \\ stolyarovevgen@mail.ru
}

\author{
Andrei Bogdanov \\ Faculty of Control System and Robotics \\ ITMO University \\ Saint-Petersburg, Russia \\ anbogdanov@itmo.ru \\ Dimid Surnin \\ Department of Electric Drives \\ Moscow Power Engineering Institute \\ Moscow, Russia \\ dimidsurnin@gmail.com
}

\author{
Galina Demidova \\ Faculty of Control System and Robotics \\ ITMO University \\ Saint-Petersburg, Russia \\ demidova@itmo.ru \\ Yuriy Vagapov \\ Faculty of Art, Science and Technology \\ Wrexham Glyndwr University \\ Wrexham, UK \\ y.vagapov@glyndwr.ac.uk
}

\begin{abstract}
The precise control of switched reluctance motor requires information about the magnetization surface as a function of rotor angular position and current. The surface can be obtained performing offline tests; however, it demands specialized mechanical equipment and time for commissioning. Moreover, the magnetization surface may be changed with the varying of the rotor and stator temperatures, which affect their dimensions and, therefore, the airgap variation. That is why the online estimation of the magnetization surface is desirable. This paper proposes the identification method operating in parallel with the model predictive current control system utilizing the magnetization map. Any error between the referenced and obtained currents is used to correct the reference points of the two-dimensional array representing the magnetization surface. The proposed method was examined using a simulation model and operated online in parallel with the primary control system driving the electrical machine.
\end{abstract}

Keywords-switched reluctance motor, magnetization surface, identification, model predictive control

\section{INTRODUCTION}

Over the past three decades, switched reluctance motors (SRM) have received much attention due to intensive development of power electronics technology and IGBTs components in particular. In terms of 3D-printing, SRM is considered as one of the best candidates to be the first commercial 3D-printed machine [1] and modular designed machine [2]-[5]. However, the electric drives based on SRM demonstrate a considerably high level of noises, vibrations, and torque ripples. The problem of torque ripples affecting both noise and vibration has been successfully solved using appropriate control techniques as reported in [6]-[8]. The best results were obtained by implementing the following two methods: (1) the direct instantaneous torque control [9] and (2) the model predictive control (MPC) [10], [11]. Both methods utilize a magnetization map as a function of rotor angular position and current or torque surface. The torque surface of the SRM can be derived from the magnetization surface and used for precise control.

The methods to obtain the magnetization surface of an SRM using special test benches are called offline methods [12], [13]. Other approaches, where the motor parameters

This work was financially supported by Government of Russian Federation, Grant 08-08. are identified under normal SRM operation, are introduced as online methods [14]. Offline methods are applied to determine the magnetization map over the entire rotor revolution, whereas online methods provide the data correction within the drive operating region only. The method reported in [14] records the voltage command data and feedback data from current sensors to build up a magnetization map. However, the sensed data always contain noise and should be filtered.

Implementation of the continuous control set (CCS) MPC of the switched reluctance drive using lookup tables [15] of the magnetization surface required solution of two problems. The first is the proper selection of representation form for the magnetization surface. In general, the magnetization surface has a high nonlinearity; it cannot be expressed as a Fourier or Tailor series with a reasonable number of coefficients to provide a desired accuracy [16]. Therefore, the best option is to use a lookup table with some interpolation method for the estimation of flux linkage between the table reference points. The lookup table can be easily adjusted using experimental data, whereas the online correction of Fourier or Tailor series coefficients is a more sophisticated procedure.

The second problem is that the accuracy of current stabilization strictly depends on the precision of the magnetization map. This feature of the CCS MPC was selected for analysis and development to use in the online identification of the magnetization surface proposed in this paper.

The proposed method operates in parallel with the CCS MPC utilizing a magnetization map. Any error between the referenced and obtained currents is processed to correct the reference points in the two-dimensional array representing the magnetization surface as a function of rotor angular position and flowing current.

\section{Continuous Control Set Model Predictive CONTROL FOR SRM}

Each phase of SRM has described by the voltage balance equation [17]:

$$
\frac{d \psi}{d t}=v-i R
$$

where $v$ is the applied voltage, $i$ is the flowing current, $R$ is the phase resistance, and $\psi$ is the flux linkage of the 


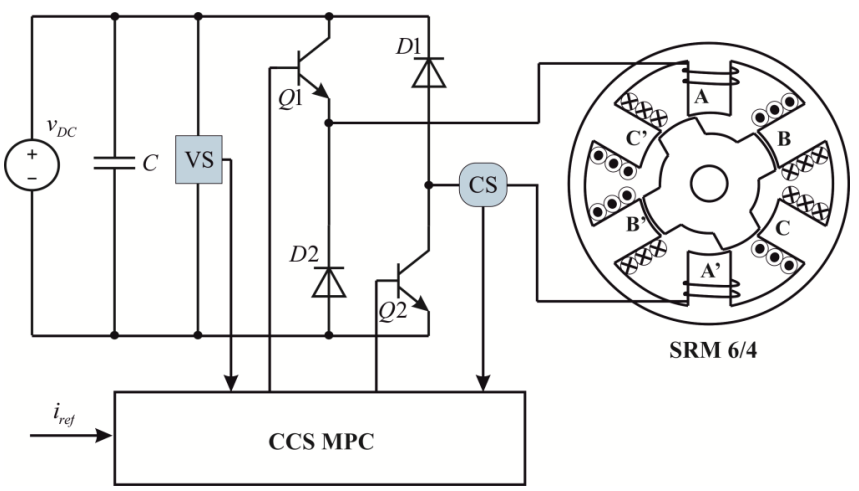

Fig. 1. Single phase control diagram (VS-voltage sensor; CS-current sensor).

winding. The motor phases are usually considered to be independent, without or with very little magnetic coupling between them [18]. Therefore, the magnetization map of each phase depends on the flowing current and the current rotor angular position.

Consider only one phase of the SRM, which is fed from its asymmetrical bridge converter presented in Fig. 1. The current regulation can be done using the magnetization surface of each motor phase. At the machine rotation and change of the current reference, the system should move from one point of the magnetization surface to another.

At the end of the PWM cycle, the current has to be measured, and the control system should process it. The control system obtains information about the measured current $i[k]$ and the current rotor electrical position $\theta[k]$. If the motor electrical speed $\omega$ is known, then the rotor position at the end of the next PWM cycle can be evaluated by:

$$
\hat{\theta}[k+1]=\theta[k]+\omega \cdot T_{P W M},
$$

where $T_{P W M}$ is the duration of the PWM cycle.

If the torque reference $T_{r e f}$ is provided, then the current reference for the next PWM cycle can be obtained from the lookup table as:

$$
i_{r e f}[k+1]=\mathrm{f}_{\text {current reference }}\left(\hat{\theta}[k+1], T_{r e f}\right),
$$

or derived directly from the speed controller if a more simple control approach is employed.

Therefore, the control system has the value of the flowing current, current rotor position, predicted rotor position for the next PWM cycle, and the current reference, which should be achieved by the current at the end of the next PWM cycle. The system moves along the magnetization surface of the motor phase form point $k$ to point $k+1$ as shown in Fig. 2.

For both points the flux linkage can be estimated as:

$$
\left.\begin{array}{l}
\hat{\psi}[k]=\mathrm{f}_{\text {magnetization surface }}(\theta[k], i[k]) ; \\
\hat{\psi}[k+1]=\mathrm{f}_{\text {magnetization surface }}\left(\hat{\theta}[k+1], i_{\text {ref }}[k+1]\right) .
\end{array}\right\}
$$

All these data can be used to solve in order to find the voltage command:

$$
v=\frac{\hat{\psi}[k+1]-\hat{\psi}[k]-\frac{i[k]+i_{r e f}[k+1]}{2} R \cdot T_{P W M}}{T_{P W M}} .
$$

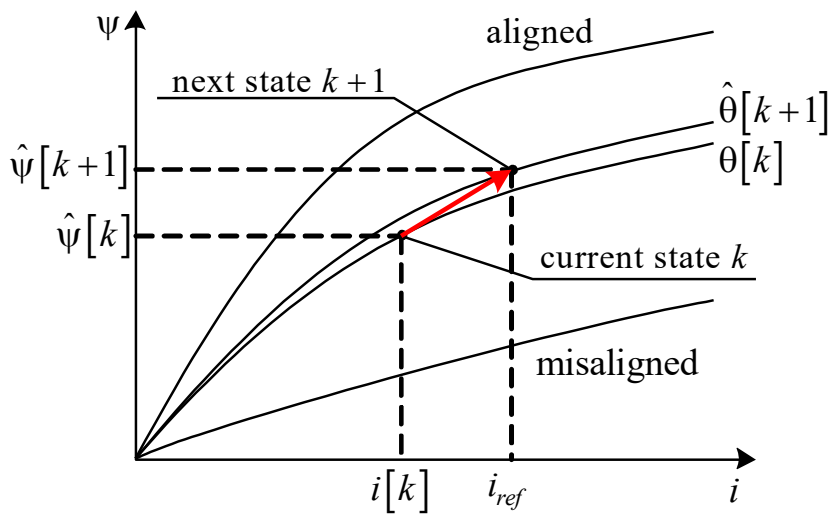

Fig. 2. Transient during a single PWM cycle.

The voltage command depends on the difference between next and current flux linkage estimations taking into account the voltage drop across the phase resistance by the average current which will flow in the winding during the next PWM cycle.

The duty cycle for the asymmetrical bridge control can be evaluated using the voltage command and the current DC link voltage $v_{D C}$ :

$$
\gamma=\frac{v}{v_{D C}}
$$

which should be limited in the range of $[-1 ;+1]$.

\section{Procedure For OnLINE IdENTIFICATION OF THE Magnetization SuRFACE}

During the operation, the considered above CCS MPC is stabilizing the current reference with some error, which depends on the accuracy of magnetization map representation. If the magnetization surface defined in the lookup table is allocated lower than the actual surface of the motor, then the current will not reach its reference as shown in Fig. 3a. If the magnetization map is defined precisely, then the current follows the reference (see Fig. 3b).

The correction of the magnetization surface reference points can be processed with respect to the error between



(a)

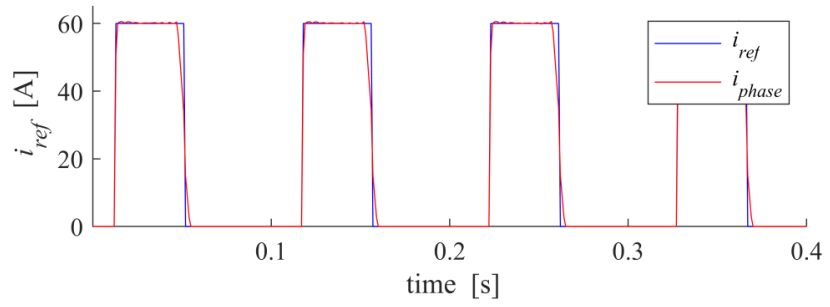

(b)

Fig. 3. Operation of the CCS MPC with error in the magnetization surface representation (a) and without (b): blue-current reference; red-flowing current. 
referenced and obtained currents. If the obtained current is smaller than the reference, it means that the actual flux linkage at this point of magnetization map is bigger than the value stored in the lookup table.

The correction should be applied for the nearest reference point of the two-dimensional array if the distance is less than one half of the distance between reference points. This ensures that only one reference point will be affected. For stability reasons, this distance can be reduced even more. The square of the distances to the reference points can be evaluated as follows:

$$
\begin{aligned}
& d_{00}^{2}=\left(\left\lfloor\frac{N}{2 \pi} \theta\right\rfloor-\frac{N}{2 \pi} \theta\right)^{2}+\left(\left\lfloor\frac{N}{I_{\max }} i_{\text {ref }}\right\rfloor-\frac{N}{I_{\text {max }}} i_{\text {ref }}\right)^{2} ; \\
& d_{01}^{2}=\left(\left\lfloor\frac{N}{2 \pi} \theta\right\rfloor-\frac{N}{2 \pi} \theta\right)^{2}+\left(\left[\frac{N}{I_{\max }} i_{\text {ref }}\right]-\frac{N}{I_{\max }} i_{\text {ref }}\right)^{2} ; \\
& d_{10}^{2}=\left(\left[\frac{N}{2 \pi} \theta\right]-\frac{N}{2 \pi} \theta\right)^{2}+\left(\left\lfloor\frac{N}{I_{\max }} i_{\text {ref }}\right\rfloor-\frac{N}{I_{\text {max }}} i_{\text {ref }}\right)^{2} ; \\
& d_{11}^{2}=\left(\left[\frac{N}{2 \pi} \theta\right]-\frac{N}{2 \pi} \theta\right)^{2}+\left(\left[\frac{N}{I_{\max }} i_{\text {ref }}\right]-\frac{N}{I_{\max }} i_{\text {ref }}\right)^{2},
\end{aligned}
$$

where $\lfloor x\rfloor$ is the floor function, $\lceil x\rceil$ is the ceil function, $N$ is the number of reference points in the array, $I_{\max }$ is the maximum current of the motor, $\theta$ is the rotor angular position, $i_{\text {ref }}$ is the referenced current, and the distances are defined as shown in Fig. 4. The squares are used to avoid evaluation of the square root, which is usually a timeconsuming computational procedure.

If the square of the distance is smaller than some specified value, for example, 0.25 , then the corresponding reference point in the magnetization surface array should be corrected with respect to the error in the current:

$$
\begin{aligned}
& \text { if }\left(d_{00}^{2}<0.25\right) \text { then } \\
& \left.\psi\left\lfloor\frac{N}{2 \pi} \theta\right\rfloor \frac{N}{I_{\max }} i_{r e f}\right\rfloor=\psi\left[\frac{N}{2 \pi} \theta\right\rfloor\left[\frac{N}{I_{\max }} i_{r e f}\right\rfloor+k\left(i_{r e f}-i\right) ; \\
& \text { if }\left(d_{10}^{2}<0.25\right) \text { then } \\
& \left.\psi_{\left[\frac{N}{2 \pi} \theta\right]\left[\frac{N}{I_{\max }} i_{\text {ref }}\right\rfloor}{ }^{*}\left[\frac{N}{2 \pi} \theta\right] \mid \frac{N}{I_{\max }} i_{\text {ref }}\right]+k\left(i_{\text {ref }}-i\right) ; \\
& \text { if }\left(d_{01}^{2}<0.25\right) \text { then }
\end{aligned}
$$

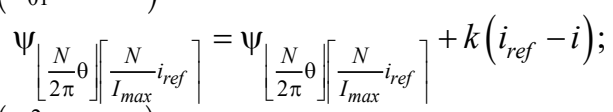

$$
\begin{aligned}
& \text { if }\left(d_{11}^{2}<0.25\right) \text { then } \\
& \Psi_{\left\lceil\frac{N}{2 \pi} \theta\right.} \theta\left[\frac{N}{I_{\max }} i_{\text {ref }}\right\rceil{ }^{*}\left\lceil\frac{N}{2 \pi} \theta\right\rceil\left[\frac{N}{I_{\max }} i_{r e f}\right]^{+k\left(i_{\text {ref }}-i\right),}
\end{aligned}
$$

where $k$ is the coefficient of the filter time constant.

\section{Simulation Results}

\section{A. Simulation Model Configuration}

There are various approaches to building a model of switched reluctance machines (SRM). One of the most convenient options for simulation is to use a linearized magnetization profile [19] shown in Fig. 5, which allows to make a fast simulation with simple equations for the torque estimation. It was assumed that the phase inductance changes according to the following equation:

$$
L=L_{a v}-\Delta L \cos \theta,
$$

where $L_{a v}$ is the average inductance, $\Delta L$ is the half difference between maximum and minimum inductances, and $\theta$ is the rotor electrical angular position.

The flux linkage of each phase can be derived from (1) after representing it using Euler integration method as:

$$
\psi_{k}=\psi_{k-1}+(v-i R) h,
$$

where $\psi_{k}$ and $\psi_{k-1}$ are the new and previous flux linkages of the motor model respectively, and $h$ is the integration step size.

The power converter shown in Fig. 1 can produce only positive current in any phase. It should be checked in the model in case of zero or negative voltage applied if the flux linkage value in the model becomes negative:

$$
\psi_{k}=\left\{\begin{array}{l}
\psi_{k}, \psi_{k} \geq 0 ; \\
0, \psi_{k}<0 .
\end{array}\right.
$$

The estimated flux linkage is applied to evaluate the value of the current flowing in the phase winding using the desaturated inductance value for that particular rotor position according to (9):

$$
i=\frac{\psi}{L} .
$$

This current can be lower or larger than the value of the saturation current. If the value is lower, then the motor operates in a linear region and no correction is required. If it is larger, then the machine is in the saturation, and the actual value of the phase current should be evaluated by:

$$
i=I_{\text {sat }}+\frac{\psi-L \cdot I_{\text {sat }}}{L_{\text {min }}}
$$

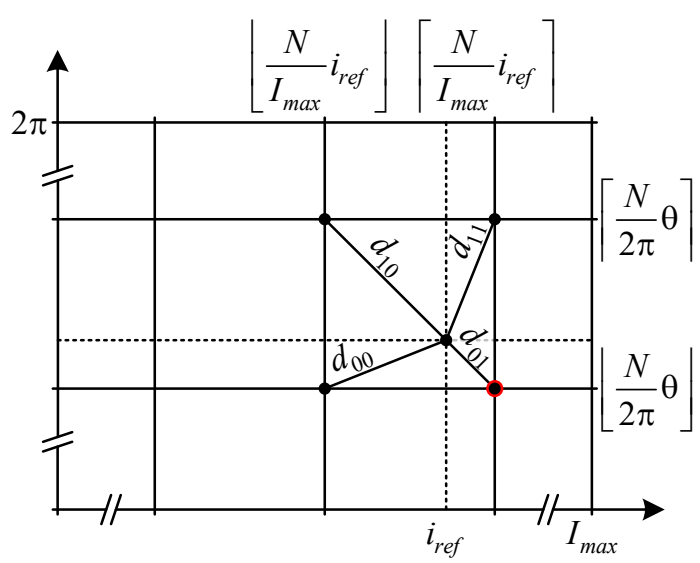

Fig. 4. Explanation of the distance evaluation.

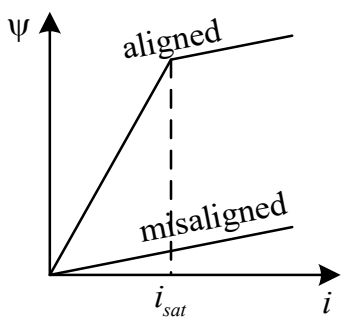

Fig. 5. Linearized magnetization profile of SRM. 
instead of (12), where $I_{\text {sat }}$ is the saturation current, and $L_{\text {min }}$ is the minimum inductance of the winding. If the flowing current is less than the saturation current value, then the torque equation of a single phase is:

$$
T=\frac{i^{2}}{2} \frac{d L(\theta)}{d \theta}=\frac{i^{2}}{2} \frac{d\left(L_{a v}-\Delta L \cos \theta\right)}{d \theta}=\frac{\Delta L}{2} i^{2} \sin \theta .
$$

Evaluation of the torque above the saturation current can be determined with the help of co-energy, which is be defined as follows:

$$
\begin{aligned}
\mathrm{W}^{\prime}(i, \theta)=\left(L_{a v}\right. & -\Delta L \cos \theta)\left(\frac{I_{\text {sat }}^{2}}{2}+I_{\text {sat }}\left(i-I_{\text {sat }}\right)\right)+ \\
& +L_{\text {min }} I_{\text {sat }}\left(i-I_{\text {sat }}\right) .
\end{aligned}
$$

Then torque can be evaluated as:

$$
T=\left.\frac{\partial \mathrm{W}^{\prime}(i, \theta)}{\partial \theta}\right|_{i}=\left(I_{s a t} i-\frac{I_{\text {sat }}^{2}}{2}\right) \Delta L \sin \theta .
$$

\section{B. Simulation Model Parameters and Results}

The current reference for each phase was set to some regulated value $i_{\text {ref. }}$. This reference was applied between some turn-on and cut-off angles 0.35 and 2.7 radians, respectively. Initially, the aligned motor inductance was taken smaller than in the controlled machine as shown in Table I. Motor was rotating at the constant speed.

For the first start of the motor, the difference in the magnetization surface parameters between the motor model and control system model results in the current following error as shown in Fig. 3a. However, after some time, the online identification procedure corrects the reference points in the flux linkage array, producing current follow the reference as shown in Fig. 3b. The magnetization surface for that current reference was partially adjusted as shown in Fig. 6a. By changing the current reference, more points of the magnetization map were adjusted as shown in Fig. $6 \mathrm{~b}$.

These results show that for precise estimation of the SRM magnetization surface, it is required to apply all variety of possible current references. The proposed solution adjusts the magnetization surface partially and needs to adapt for the particular operating conditions.

TABle I. SRD PARAMETERS.

\begin{tabular}{|l|l|l|}
\hline \multicolumn{1}{|c|}{ Parameter } & \multicolumn{1}{|c|}{ Value } & Units \\
\hline Misaligned motor inductance & 10.0 & $\mathrm{mH}$ \\
\hline Aligned motor inductance & 100.0 & $\mathrm{mH}$ \\
\hline Saturation current & 20 & $\mathrm{~A}$ \\
\hline Phase resistance & 0.05 & $\mathrm{Ohm}$ \\
\hline Pole pairs & 4 & - \\
\hline Maximum phase current limit & 100 & $\mathrm{~A}$ \\
\hline DC link voltage & 600 & $\mathrm{~V}$ \\
\hline PWM frequency & 2.0 & $\mathrm{kHz}$ \\
\hline Electrical angular velocity & 598 & $\mathrm{rad} / \mathrm{s}$ \\
\hline Turn-on angle & 0.35 & $\mathrm{rad}$ \\
\hline $\begin{array}{l}\text { Cut-off angle } \\
\text { Misaligned initial motor inductance in the } \\
\text { Aligned initial motor inductance in the } \\
\text { control system }\end{array}$ & 10.0 & $\mathrm{mH}$ \\
\hline
\end{tabular}

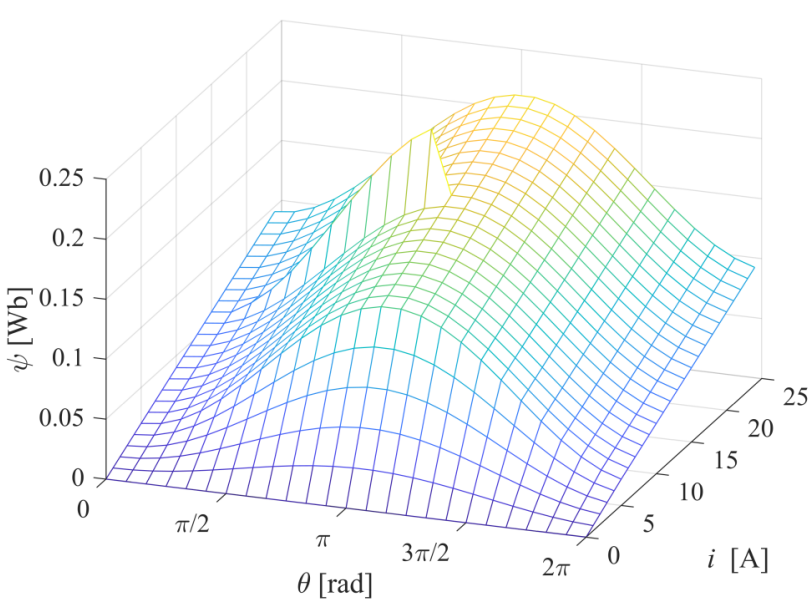

(a)



(b)

Fig. 6. Adjustment of the magnetization surface by the proposed online identification procedure: (a) after the operation with the constant current reference; (b) after the longer operation with various current references.

\section{Conclusion}

The proposed online identification procedure estimates the magnetization surface in the range of operating currents and commutation angles of the SRM. It employs the firstorder filtering to exclude measurement error impact and to increase the stability of the control system. This identification method can be run in parallel with the control system correcting, for example, airgap change caused by the difference in the stator and rotor temperatures.

The future research will be devoted to experimental verification of the proposed solution.

\section{REFERENCES}

[1] A. Rassõlkin, A. Kallaste, T. Vaimann, and H. Tiismus, "Control challenges of 3D printed switched reluctance motor," in Proc. 26th Int. Workshop on Electric Drives: Improvement in Efficiency of Electric Drives (IWED), Moscow, Russia, 30 Jan.-2 Feb. 2019, pp. 1-5, doi: 10.1109/IWED.2019.8664282.

[2] P. Andrada, B. Blanqué, E. Martínez, J.I. Perat, J.A. Sánchez, and M. Torrent, "Design of a novel modular axial-flux double rotor switched reluctance drive," Energies, vol. 13, no. 5, Mar. 2020, Art. no. 1161, doi: 10.3390/en13051161.

[3] M. Ruba, I. Benţia, and L. Szabó, "Modular fault tolerant switched reluctance machine - design and dynamic simulations," in Proc. 12th Int. Conf. on Optimization of Electrical and Electronic Equipment, Basov, Romania, 20-22 May 2010, pp. 441-446, doi: 10.1109/ OPTIM.2010.5510431. 
[4] M. Ruba, I. Bentia, and L. Szabó, "Novel modular switched reluctance machine for safety-critical applications," in Proc. XIX Int. Conf. on Electrical Machines - ICEM 2010, Rome, Italy, 6-8 Sept. 2010, pp. 1-6, doi: 10.1109/ICELMACH.2010.5607971.

[5] L. Szabó, "Advancements in electrical machines design brought by the modular construction," in Proc. X Int. Conf. on Electrical Power Drive Systems (ICEPDS), Novocherkassk, Russia, 3-6 Oct. 2018, pp. 1-6, doi: 10.1109/ICEPDS.2018.8571897.

[6] M. Zhang, I. Bahri, X. Mininger, C. Vlad, H. Xie, and E. Berthelot, "A new control method for vibration and noise suppression in switched reluctance machines," Energies, vol. 12, no. 8, Apr. 2019, Art. no. 1554, doi: 10.3390/en12081554.

[7] L. Huang, Z.Q. Zhu, J.H. Feng, S.Y. Guo, Y.F. Li, and J. Shi, "Novel current profile of switched reluctance machines for torque density enhancement in low-speed applications," IEEE Trans. on Industrial Electronics, to be published, doi: 10.1109/TIE.2019.2952801.

[8] J. Ye, B. Bilgin, and A. Emadi, "An offline torque sharing function for torque ripple reduction in switched reluctance motor drives," IEEE Trans. on Energy Conversion, vol. 30, no. 2, pp. 726-735, June 2015, doi: 10.1109/TEC.2014.2383991.

[9] R.B. Inderka, and R.W.A.A. De Doncker, "DITC-direct instantaneous torque control of switched reluctance drives," IEEE Trans. on Industry Applications, vol. 39, no. 4, pp. 1046-1051, JulyAug. 2003, doi: 10.1109/TIA.2003.814578.

[10] H. Peyrl, G. Papafotiou, and M. Morari, "Model predictive torque control of a switched reluctance motor," in Proc. IEEE Int. Conf. on Industrial Technology, Gippsland, Austalia, 10-13 Feb. 2009, pp. 16, doi: 10.1109/ICIT.2009.4939734.

[11] A. Anuchin, V. Podzorova, V. Popova, I. Gulyaev, F. Briz, and Y. Vagapov, "Model predictive torque control of a switched reluctance drive with heat dissipation balancing in a power converter," in Proc. 60th IEEE Int. Sci. Conf. on Power and Electrical Engineering of Riga Technical University (RTUCON), Riga, Latvia, 7-9 Oct. 2019, pp. 1-6, doi: 10.1109/RTUCON48111.2019.8982255.
[12] P. Chancharoensook, and M.F. Rahman, "Magnetization and static torque characterization of a four-phase switched reluctance motor: experimental investigations," in Proc. 4th IEEE Int. Conf. on Power Electronics and Drive Systems, Denpasar, Indonesia, 25-25 Oct. 2001, vol. 2, pp. 456-460, doi: 10.1109/PEDS.2001.975359.

[13] C. Cossar, and T.J.E. Miller, "Electromagnetic testing of switched reluctance motors," in Proc. Int. Conf. on Electrical Machines, Manchester, UK, 15-17 Sept. 1992, pp. 470-494.

[14] C. Cossar, M. Popescu, T. Miller, and M. McGilp, "On-line phase measurements in switched reluctance motor drives," in Proc European Conf. on Power Electronics and Applications, Aalborg, Denmark, 2-5 Sept. 2007, pp. 1-8, doi: 10.1109/EPE.2007.4417358.

[15] A. Anuchin, C. Hao, A. Bogdanov, G. Demidova, A. Zharkov, and V. Smidl, "Continous control set model predictive control of a switch reluctance drive using lookup tables," unpublished.

[16] C. Li, G. Wang, J. Liu, Y. Li, and Y. Fan, "A novel method for modeling the electromagnetic characteristics of switched reluctance motors," Applied Sciences, vol. 8, no. 4, Mar. 2018, Art. no. 537, doi: 10.3390/app8040537.

[17] R. Krishnan, Switched Reluctance Motor Drives: Modeling Simulation Analysis Design and Applications. Boca Raton, FL, USA: CRC Press, 2001

[18] B. Parreira, S. Rafael, A.J. Pires, and P.J.C. Branco, "Obtaining the magnetic characteristics of an 8/6 switched reluctance machine: from FEM analysis to the experimental tests," IEEE Trans. on Industrial Electronics, vol. 52, no. 6, pp. 1635-1643, Dec. 2005, doi: 10.1109 TIE.2005.858709.

[19] A. Anuchin, D. Grishchuk, A. Zharkov, Y. Prudnikova, and L. Gosteva, "Real-time model of switched reluctance drive for educational purposes," in Proc. 57th IEEE Int. Sci. Conf. on Power and Electrical Engineering of Riga Technical University (RTUCON), Riga, Latvia, 13-14 Oct. 2016, pp. 1-5, doi: 10.1109/ RTUCON.2016.7763099. 